\title{
Cluster Preface: Integrated Synthesis Using Continuous-Flow Technologies
}

\author{
Shinichiro Fuse* \\ Graduate School of Pharmaceutical Sciences, Nagoya \\ University, Furo-cho, Chikusa-ku Nagoya, 464-8601, Japan \\ fuse@ps.nagoya-u.ac.jp \\ Dedicated to the memory of Prof. Jun-ichi Yoshida \\ Published as part of the Cluster Integrated Synthesis Using \\ Continuous-Flow Technologies
}

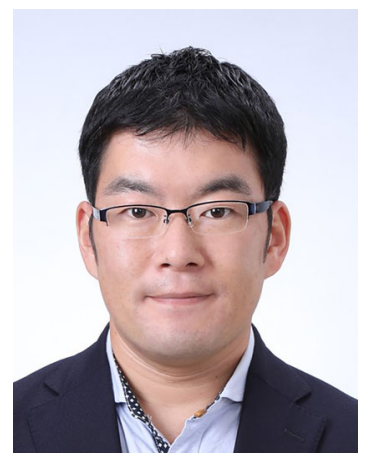

Received: 10.11.2020

Accepted after revision: 10.11.2020

Published online: 17.11 .2020

DOI: 10.1055/s-0040-1706605; Art ID: st-2020-u4444-c

Shinichiro Fuse was born in 1977 in Japan. He earned his B.S. degree in 2000 and his Ph.D. in 2005 from Tokyo Institute of Technology under the supervision of Prof. Takashi Takahashi. He was a researcher at ChemGenesis Incorporated between 2005 and 2006, and a postdoctoral fellow from 2006 to 2008 at Harvard University in the group of Prof. Daniel E. Kahne. In 2008, he joined the faculty at the Tokyo Institute of Technology as an assistant professor. He then moved to the Chemical Resources Laboratory at the same university as an associate professor in 2015. He was appointed as a professor at Nagoya University in 2019. His research is aimed toward the development of efficient synthetic processes based on a deep understanding of organic chemistry using flow synthesis, automated synthesis, theoretical calculations, and machine-learning technologies.

The last two decades have witnessed the creation of highly efficient synthetic processes that were realized by using the following advantages of continuous-flow technologies:

(1) Precise control of short reaction times and temperatures. ${ }^{1}$

(2) Minimized risks in handling dangerous compounds. ${ }^{2}$

(3) Ease in scaling-up syntheses. ${ }^{3}$

Selectivities and/or yields of reactions can be improved by using continuous-flow technologies. In addition, the avoidance of using very low temperature conditions can reduce energy consumption, ${ }^{4}$ whilst the smaller footprint of continuous-flow reactors is another big merit. ${ }^{5}$ These advantages result in both reduction of the costs and the waste produced during chemical processes. This is also important from an environmental point of view. ${ }^{6}$

The integration of multiple reactions in continuousflow reactors further enhances synthetic efficiency because tedious intermediate purifications can be reduced. In addition, combinations of in-line monitoring systems with con- tinuous-flow systems enable rapid data acquisition. ${ }^{7}$ These technologies are not only valuable for rapid optimization of reaction conditions and for gaining insights into reaction mechanisms, but also for Quality by Design (QbD) based process control in future industrial-scale synthesis. Furthermore, the integration of machine-learning with continuous-flow synthesis and in-line monitoring technologies enables autonomous rapid optimization of processes. ${ }^{8}$ The COVID-19 pandemic has led to an increased focus on automated and remote synthesis in the field of organic chemistry field. Originally, the affinity between continuous-flow synthesis and automated synthesis was high. ${ }^{8}$ Integrated continuous-flow technologies provide a strong boost to automated and remote synthesis. Therefore, the development of novel reactions, methods, and equipment that will contribute to integrated flow synthesis is important.

I am delighted to receive 13 important contributions from across the globe for this SYNLETT Cluster. The reported reactions and additional technologies used are summarized in Table 1 . The integration of various technologies such as inductive heating, fine-bubble-slug-flow, photochemical reactions, electrochemical reactions, automated synthesis, and liquid-liquid separation has further enhanced process efficiency.

Okano and co-workers demonstrated lithiation of dibromothiophenes and their electrophilic trapping. They were able to successfully avoid the undesired halogen dance by integration of the reactions. ${ }^{9}$ Watts and Sagandira achieved the high-yielding (9 steps, 54\%) continuous-flow synthesis of (-)-oseltamivir phosphate. The use of continuous-flow technology reduced the risk in handling dangerous compounds such as an azide and an aziridine. ${ }^{10}$ Nagaki and coworkers have demonstrated the $n-\mathrm{Bu}_{3} \mathrm{SnH}$-mediated reduction of alkyl halides in a flow microreactor. They used an interesting technique: Sequential portionwise injection of an initiator maintained a low concentration of the alkyl tin radical so as to avoid its deactivation. ${ }^{11}$ Knochel et al. have clearly summarized organometallic ( $\mathrm{Li}, \mathrm{Na}$, and $\mathrm{K}$ ) reactions 
in continuous-flow reactors, with the advantages of using flow processes in handling the unstable organometallic species. ${ }^{12}$ Shindo and co-workers have demonstrated ynolate formation/benzyne formation/triple cycloaddition for the synthesis of triptycene. All these steps were conducted in only 1 minute by using a continuous-flow reactor. ${ }^{13}$ Kirschning and Oltmanns have reported an 0 -allylation/Claisen rearrangement sequence. Subsupercritical water, generated by inductive heating, was used to accelerate the Claisen rearrangement in a continuous-flow reactor. ${ }^{14}$

Mase and co-workers demonstrated an efficient hydrogenation of various alkenes and alkynes using a fine-bubble-slug-flow approach. They achieved higher productivity and selectivity compared with conventional slug-flow or bubbling approaches. ${ }^{15}$ Mitsudo, Suga, and co-workers have achieved a telescoped four-step synthesis of a [1]benzothieno[3,2-b][1]benzothiophene (BTBT) derivative. ${ }^{16}$ Meanwhile, Baxendale and co-workers have described the successful integration of photo and thermal processes for the synthesis of oximes. Additionally, an interesting recycling process for substrates used in excess was introduced. ${ }^{17}$ Wirth and Amri reported a highly efficient, automated, continuous-flow, electrochemical synthesis of various chalcogenophosphonates. ${ }^{18} \mathrm{Kim}$ et al. have demonstrated an integrated lithium-halogen exchange/electrophilic trap-

Table 1 A Summary of the Contributions to this SYNLETT Cluster

\begin{tabular}{|c|c|c|}
\hline Author(s) & Reported reactions & Additional technologies \\
\hline Okano & lithiation/electrophilic trapping & - \\
\hline Watts & $\begin{array}{l}\text { mesylation/azidation/aziridina- } \\
\text { tion/aziridine ring-opening/ } \\
\mathrm{N}-\mathrm{P} \text { bond cleavage/acetyla- } \\
\text { tion/azidation/azide reduction }\end{array}$ & - \\
\hline Nagaki & radical chain reaction & - \\
\hline Knochel & $\begin{array}{l}\text { organometallic ( } \mathrm{Li}, \mathrm{Na} \text {, and K) re- } \\
\text { actions }\end{array}$ & - \\
\hline Shindo & $\begin{array}{l}\text { ynolate formation/benzyne for- } \\
\text { mation/triple cycloaddition }\end{array}$ & - \\
\hline Kirschning & $\begin{array}{l}\text { O-allylation/Claisen rearrange- } \\
\text { ment }\end{array}$ & $\begin{array}{l}\text { inductive heating, sub- } \\
\text { supercritical } \mathrm{H}_{2} \mathrm{O}\end{array}$ \\
\hline Mase & hydrogenation & fine-bubble-slug-flow \\
\hline $\begin{array}{l}\text { Mitsudo, } \\
\text { Suga }\end{array}$ & $\begin{array}{l}\text { Friedel-Crafts-type cycliza- } \\
\text { tion/thioetherification/Pd-cata- } \\
\text { lyzed dehydrogenative cyclization }\end{array}$ & - \\
\hline Baxendale & $\begin{array}{l}\text { nitrosation/thermal fragmenta- } \\
\text { tion of diazenes }\end{array}$ & $\begin{array}{l}\text { photo reaction, contin- } \\
\text { uous recycling }\end{array}$ \\
\hline Wirth & $\begin{array}{l}\text { selenylation and thiolation of } \\
\text { phosphonates }\end{array}$ & $\begin{array}{l}\text { electrochemical reaction, } \\
\text { automated synthesis }\end{array}$ \\
\hline Kim & $\begin{array}{l}\text { Lithium-halogen exchange/elec- } \\
\text { trophilic trapping/nucleophilic } \\
\text { addition }\end{array}$ & - \\
\hline Jamison & $\begin{array}{l}\text { Mannich reaction/Grignard reac- } \\
\text { tion }\end{array}$ & $\begin{array}{l}\text { liquid-liquid separation, } \\
\text { slug-flow, in-line FT-IR }\end{array}$ \\
\hline $\begin{array}{l}\text { Shimizu, } \\
\text { Hachiya }\end{array}$ & Grignard reactions/oxidation & - \\
\hline
\end{tabular}

ping/nucleophilic addition sequence, in which side reactions were successfully suppressed using continuousflow technology. ${ }^{19}$ Jamison and co-workers have described a one-flow, two-step synthesis of tramadol from cyclohexanone that involves Mannich and Grignard reactions. They successfully performed not only reactions but purification of the products by a phase-separation technique in an automated fashion. ${ }^{20}$ Shimizu, Hachiya and co-workers have demonstrated an integrated synthesis of tetrasubstituted $\alpha$ amino acids via sequential trialkylation using a micro-flow reactor. They were able to perform their syntheses in short reaction times without using very low temperature conditions. ${ }^{21}$

All these contributions clearly show significant promise and further scope for future advancements in the field of integrated continuous-flow synthesis. I am sincerely appreciative to all the distinguished scientists for their excellent contributions to this SYNLETT Cluster.

\section{Funding Information}

I am grateful for the financial support from the Japan Science and Technology Agency, JST-Mirai Program (Grant no. JPMJMI18G7), the Japan Society for the Promotion of Science (JSPS) KAKENHI (Grant nos. $17 \mathrm{H} 03053$ and 20K21188) and the Ministry of Education, Culture, Sports, Science and Technology (MEXT), Scientific Research on Innovative Areas 2707 Middle molecular strategy (Grant no. 16H01138).

\section{References}

(1) (a) Yoshida, J.-i. Flash Chemistry: Fast Organic Synthesis in Microsystems 2008. (b) Yoshida, J.-i.; Saito, K.; Nokami, T.; Nagaki, A. Synlett 2011, 1189.

(2) Kockmann, N.; Thenée, P.; Fleischer-Trebes, C.; Laudadio, G.; Noël, T. React. Chem. Eng. 2017, 2, 258.

(3) Anderson, N. G. Org. Process Res. Dev. 2012, 16, 852.

(4) Colella, M.; Nagaki, A.; Luisi, R. Chem. Eur. J. 2020, 26, 19.

(5) Baumann, M.; Moody, T. S.; Smyth, M.; Wharry, S. Org. Process Res. Dev. 2020, 24, 1802.

(6) Rogers, L.; Jensen, K. F. Green Chem. 2019, 21, 3481.

(7) Ley, S. V.; Fitzpatrick, D. E.; Ingham, R. J.; Myers, R. M. Angew. Chem. Int. Ed. 2015, 54, 3449.

(8) Mateos, C.; Nieves-Remacha, M. J.; Rincón, J. A. React. Chem. Eng. 2019, 4, 1536.

(9) Okano, K.; Yamane, Y.; Nagaki, A.; Mori, A. Synlett 2020, 31, 1913.

(10) Sagandira, C. R.; Watts, P. Synlett 2020, 31, 1925.

(11) Jiang, Y.; Ashikari, Y.; Guan, K.; Nagaki, A. Synlett 2020, 31, 1937.

(12) Harenberg, J. H.; Weidmann, N.; Knochel, P. Synlett 2020, 31, 1880.

(13) Iwata, T.; Yoshinaga, T.; Shindo, M. Synlett 2020, 31, 1903.

(14) Oltmanns, M.; Kirschning, A. Synlett 2020, 31, 1942.

(15) Iio, T.; Nagai, K.; Kozuka, T.; Sammi, A. M.; Sato, K.; Narumi, T.; Mase, N. Synlett 2020, 31, 1919.

(16) Mitsudo, K.; Habara, N.; Kobashi, Y.; Kurimoto, Y.; Mandai, H.; Suga, S. Synlett 2020, 31, 1947.

(17) Griffiths, O. M.; Ruggeri, M.; Baxendale, I. R. Synlett 2020, 31, 1907.

(18) Amri, N.; Wirth, T. Synlett 2020, 31, 1894.

(19) Lee, H.-J.; Torii, D.; Jeon, Y.; Yoshida, J.-i.; Kim, H. Synlett 2020, 31, 1899.

(20) Monos, T. M.; Jaworski, J. N.; Stephens, J. C.; Jamison, T. F. Synlett 2020, 31, 1888.

(21) Ota, K.; Fukumoto, S.; Iwase, T.; Mizota, I.; Shimizu, M.; Hachiya, I. Synlett 2020, 31, 1930. 